\title{
Editorial
}

\section{Congenital and Structural Heart Diseases: We are in Progress}

\author{
Nurun Nahar Fatema
}

(Bangladesh Heart Journal 2018; 33(2): 78-79)

Congenital heart disease (CHD) refers to structural or functional heart disease present at birth, even if first discovered later. The incidence of congenital heart disease is the rate that refers to the number of children born with congenital heart disease related to the total number of births over a period of one year. Incidence varies from 6-8/1000 live births in various studies conducted in many centers. In Bangladesh incidence was found up to 25/1000 live births in one year in a study conducted in Combined Military Hospital (CMH), Dhaka. Infant mortality rate of 54/1000 live births in the country is also contributed a lot by the death of infants from congenital heart disease.

There are 8 common lesions which account for about $80 \%$ of all congenital lesions. They are in descending order of prevalence are ventricular septal defect (VSD, 30\%), patent ductus arteriosus(PDA, 10\%), atrial septal defect (ASD, 8\%), pulmonary stenosis (PS, 8\%), coarctation of aorta (CoA, 5$6 \%$ ), aortic stenosis (AS, $5-6 \%$ ), transposition of great arteries (TGA, $4-5 \%$ ). The remaining $20 \%$ or so is made of a variety of rarer or complex lesions.

The important pediatric cardiac milestones are successful PDA ligation in 1938 in USA, coarctation repair in 1945 in USA, ASD closure in 1953 by Gibbon in USA. The life-saving intervention of balloon atrial septostomy was first performed in late 1960 by Rashkind in Philadelphia, USA. In late 1970, introduction of prostaglandin for treatment of ductus dependent pulmonary and systemic circulation provides a measure of securing adequate oxygenation in a number of blue neonates, thus delaying emergency intervention and surgery by keeping them alive. On the other hand, indomethacin is used to close the haemodynamically

Address of Correspondence : Brig. Gen. Nurun Nahar Fatema, Head of Paediatric Cardiology and Paediatrics , Combined Military Hospital Dhaka, Bangladesh. Mobile: +8801819239021, E.mail: colfatema@hotmail.com significant PDA in new born. First percutaneous PDA occlusion was performed in 1967 by Portsmann et al.and first ASD device closure was done by King and Mill in 1976. First balloon valvuloplasty was introduced in 1979. First VSD device closure was performed in 1990s. Amplatzer septal occluder was first described in 1997. Melody valve for percutaneous pulmonary valve implantation was innovated in 2000 .

As incidence of CHD is increasing, the magnitude of the problem is becoming enormous in our country. There was not a single pediatric cardiology-trained person in the country until a team started work in $\mathrm{CMH}$, Dhaka after training from Prince Sultan Cardiac Centre (PSCC), Riyadh, KSA in August 1998. That team was composed of paediatric cardiologist, anesthesiologist, surgeon along with echo, cath lab, operation theatre (OT), and intensive care unit (ICU) technicians. PSCC donated cath lab disposables and interventional hardwires to pediatric cardiologist in sufficient amount so that work could be started immediately. So, all possible interventions were started after commencement of thatunit. Following are the list of important milestones of congenital cardiac interventions in Bangladesh.

Pulmonary valve replacement first ever in South Asia with Melody valve 2012, balloon atrial septostomy (reported) in 1999, PDA coil occlusion in 1998, pulmonary valvoplasty in infant in 1999, ASD device closure in 2001, muscular VSD device closure in 2005, perimembranous VSD device closure in 2006,PDA device closure in 2003, coronary cameral fistula closure in 2010, PDA stenting in 2006 in pulmonary atresia, VSD coil occlusion in 2007 , huge tubular PDA closure in 2007, CoA balloon angioplasty in newborn in 2001 , aortic balloon valvuloplasty for critical aortic stenosisin 2001, right ventricular outflow tract (RVOT) stenting in double outlet right ventricle (DORV),VSD,PS in 2007, patent foramen ovale(PFO) closure in 2010.All these interventions were performed in catheterization laboratory of $\mathrm{CMH}$, Dhaka. 
Many interventions were life-saving for newborn and young infant and those were performed routinely with excellent outcomes. Later, other cardiac hospitals started pediatric cardiac programs and delivering services to the large number of children suffering from CHDs.

There was glorious history of congenital cardiac surgeries since late 70's. In Bangladesh, first ever Blalock Taussig (BT) shunt was performed in early 80's in National Institute of Cardiovascular Diseases(NICVD) by Prof. S R Khan. (Information of first ever surgeries are collected from a presentation of Prof. Asit Baran Adhikary in Dhaka Shishu Hospital). Ligation of PDA was performed in 1979(Prof.S R Khan and team ), ASD closure in 1981 (Prof. NAKhan and team), VSD closure in 1991(Prof S R Khan and team), successful tetralogy of Fallot (TOF) repair in 1992(S R Khan and team), bidirectional Glenn shunt in 1995 (Prof. SR Khan and team), Mustard operation in 1996 (Prof. SR Khan and team), modified Fontan operation in 1997 (Prof. SR Khan and team), Senning operation in 2001(Asit Baran Adhikary and team), rerouting of total anomalous pulmonary venous connections (TAPVC) in 2002(Asit Baran Adhikary and team), Lecompte procedure in 2006 (Asit Baran Adhikary and team), arterial switch operation in 2007 (Jahangir Kabir and team). Continuous growth in this sector was interrupted for many reasons. Later, congenital heart surgeries started in National Heart Foundation Hospital \& Research Institute (NHF\&RI) and the center is now playing a major rolein treating congenital cardiac cases. Ibrahim Cardiac Hospital \& Research Institute (ICH\&RI) is giving support for charity cardiac surgery program for poor people in association with Al Muntada Aid, UK. Many other cardiac centers are also progressing as per capabilities.

Other than interventions and surgeries, many patientsalso require medical interventions among which maintenance of
PDA in duct dependent lesion (by IV prostaglandin), closure of PDA (by IVindomethacin, ibuprofen, paracetamol) and treatment of persistent pulmonary hypertension in newborn, various arrhythmias, heart failure, cardiomyopathies are important.

Though many centers are now working with CHDs, still large number of patients are going to neighboring countries specially for neonatal, high risk and complex surgeries. Moreover, most of the children are poor and cannot afford treatment even inside country. Many charity programs are going on to meet the need of these group of patients among which Child Heart Trust(CHTB) is playing a major role by raising fund and involving foreign charity groups like Little Heart, KSA, Al Muntada, UK and Qatar Red Crescent Charity. Some charity groups are helping poor patients as part of technology transfer program to some cardiac hospitals.

Paediatric cardiology and cardiac surgery are the most difficult subspecialty, need long uninterrupted training from good centers, hard work, devotion, honesty and sincerity. Most importantly, these two groups of specialists need support from skilled anesthesiologists and intensivists. There is scarcity of dedicated pediatric cardiac anesthesiologists and intensivists in Bangladesh and these two groups must be strong to bring successful outcomes of any surgery or intervention.

Hopefully, in coming years we will be able to fulfill the need of our patients completely by development of skill from good quality training and initiation of formal course dedicated to pediatric cardiology, pediatric cardiac surgery, pediatric cardiac anesthesia and pediatric cardiac intensive care. 